\title{
A CONDESOSA DA MALDADE: formação da personagem feminina no romance brasileiro do século XIX
}

Adeítalo Manoel Dinho

Este trabalho é parte de estudo anterior, apresentado no Seminário 'Literatura e Mulher' (2006), quando, na oportunidade, discuti sobre a permanência do mito de Pandora na modernidade, e posterior, a respeito da literatura de jornal. Nesse último caso, me interessa a peculiaridade da literatura publicada em ambiente de periódico.

De forma alguma é incomum a literatura conceber modelos femininos negativos como oportunidade didática. Em A condessa Vésper (Memórias de um condenado 1882, e Condessa Vésper - 1902), o polêmico escritor Aluísio Azevedo (1857-1913) constrói uma protagonista demônio. Hiperbolicamente negativa, Ambrosina oferece oportunidade de ampliar o elenco de perfis femininos da literatura brasileira e aprofundar os códigos estéticos e sociais que dão vazão ao aparecimento de literaturas com esse caráter. A leitura tenta aliar as duas áreas de estudo da literatura, crítica literária e historiografia da literatura. Ambas costumam argumentar que os livros são motivo de consagração pela sua formatação e requinte, dados pelo seu autor. Coincidentemente, as duas áreas de estudos literários elegem livros em que as personagens femininas se encaminham por uma linha negativa, na sua aparição social, da ficção, e deflagrando punições que parecem satisfazer essas análises.

A condessa Vésper (1902) conta a história da protagonista, em meio a uma série de acontecimentos que se desenvolvem desde antes de seu nascimento até depois de 
sua morte. O romance é publicado pela primeira vez em folhetim no polêmico jornal A gazetinha, de propriedade de Arthur Azevedo, irmão do escritor. Se há elementos sensacionalistas no acontecimento de uma moça da sociedade, mais por ambição do que por amor, transformar-se (para gosto do público leitor) em noiva-viúva (quando o seu marido enlouquece na noite de núpcias), em amásia (quando vai morar com a personagem Gabriel), criminosa, quando foge carregando consigo dinheiro do amante, e homossexual, quando leva junto a inocente Laura, essas peripécias organizam e repetem hiperbolicamente um perfil ficcional consagrado para o feminino.

Na literatura, há uma série de personagens femininas construídas com características desordenadoras. Elas são postas na ficção como um obstáculo que o homem deve superar. São negativas e por isso opóem-se a toda positividade que significa o homem. N'A Moreninha, de Joaquim Manoel de Macedo, elas são qualificadas de 'maitracas', tal é a sua capacidade de fazer barulho, ou preocupar-se com coisas insignificantes. São, portanto, fúteis. Romances como Senhora, Luciola ou a grande maioria dos de José de Alencar, Dom Casmurro e A mão e a luva, de Machado de Assis, são exemplos de arrumação estética e motivo de festejo dos livros e de seus autores. Essas obras permitem que tranquilamente haja um desnível ou desequilíbrio dos gêneros (o que de forma alguma é demérito, pois há outros bons livros em que a personagem feminina trilha ou parece trilhar uma construção mais positiva, concluindo com a edificação e não com a punição - de que são exemplos autores como Guimarães Rosa e Jorge Amado.). Raramente é um desnível onde o homem termina punido.

A narrativa de Senhora parece ser uma simulação progressista, porém, não há de fato uma mobilidade de identidade masculina, que permanece a mesma, e ironicamente é recompensada na conclusão da narrativa. Enquanto a personagem feminina, que se disfarça de avançada e crítica para retornar à posição reacionária de mulher submissa, quando, da pior maneira, ao menos poderia constituir-se nas matronas masculinizadas de que reclama Gilberto Freyre, em seu Casa-grande \& senzala. "Personagens como Capitu, Desdêmona e Madame Bovary ${ }^{1}$ trazem a mesma marca da destruição de Psiqué, Helena e Pandora”. Daí porque sempre temos que ter cuidado com a nomenclatura teórica, para que não confundamos com personagens femininas da literatura aquelas que encontramos no real (lembrando uma questáo respondida pela professora Regina Zilberman, de maneira áspera, na UNISINOS, 2004). Mesmo sabendo que as duas entidades se confundem na linguagem. E um discurso (literatura ou organização social) deseja moldar e/ou ser moldado pelo outro.

Os motivos da qualificação literária estariam numa escolha histórica, na qual homens e mulheres devem ocupar lugares opostos. Se o homem é todo positivo, a 
mulher é proporcionalmente negativa; se ao homem sobra o fardo do domínio, à mulher resta ser dominada. Duas negativas são fundamentais nessa adjetivação. Eva e Pandora. Dois ícones míticos e morais da cultura ocidental que norteiam indagaçôes nas diversas áreas, fazendo filósofos, físicos, matemáticos e literatos tomar posturas semelhantes. Elas são os motivos para o feminino tomar o lugar de opositor e viláo nos enredos narrativos de cunho moralizante.

Se, nos romances-folhetins, o que se mostra na superfície é a história de amor (no caso, entre Ambrosina e Gabriel), o mecanismo que a conecta ao leitor é a sua capacidade de conduzir uma moral integral, no início, que será questionada, no decorrer dos capítulos, e chamará a atenção do público para o seu caráter antagônico. Resta a sua reconstituição, com recursos como a punição, no discurso moral, e exemplos de conduta saudável. É o uso habilidoso de atributos narrativos entre a fértil etapa de restabelecimento da ordem e o seu rápido final que se estabiliza e, de certa forma, dá sentido ao folhetim.

Em se tratando de um gênero no qual os capítulos vão saindo à medida que os leitores aprovam ou náo o que leem, surge um pacto entre o escritor e o público. Os laços de recepção são os mais fortes, demonstrando a interatividade na composição literária e também uma ligação íntima entre produtor e consumidor, contando aí seus códigos ideológicos; significa dizer que o escritor nunca está sozinho na publicação das ideias nos textos, sejam avançadas ou reacionárias.

Vale destacar que Aluísio Azevedo é o escritor que, na época, não mediu esforços para bater-se com a sociedade (entenda-se leitores), haja vista o seu livro anterior, $O$ mulato, ter causado a sua saída de Sáo Luís e a vinda para o Rio de Janeiro. Sendo assim, há um diálogo entre escritor e público, determinando até uma certa parceria e isto pode ter ocorrido, na medida dos limites das duas partes, na ficçáo em estudo. Irremediavelmente, a vida e obra estão indissociáveis. Isto significa que a relação entre o escritor e o público não é simplesmente cordial, porque a consagração não é a única motivação para a escrita; junte-se aí a discordância com a forma conservadora da sociedade. Apesar de não ser iniciante e já ter certo prestígio, por causa dos livros anteriores, Azevedo precisava de algo mais: sobreviver de literatura.

O autor de Casa de pensão é um exemplo de literatura muito raro nas histórias e, não obstante, muito comum na literatura: fazer romance é profissão e, por isso, precisa envolver dinheiro. Os diálogos entre Anselmo/Coelho Neto e Rui Vaz/Aluísio Azevedo, no romance $A$ conquista ${ }^{2}$, demonstram o drama de produtores de literatura que detestam abrir mão de seu modelo de fazer literário e intelectual, mas também precisam viver de sua arte. Depois, As memórias de um condenado, quando transformadas em livro, levam 
consigo um agradecimento ao editor, que, tanto quanto o público, é responsável pelo sustento do escritor. É função da historiografia detectar em que momento a mira da avaliação literária deixou de acertar no alvo que é a obra, para atacar, nesse mesmo alvo, os limites da moralidade social: moralidade estética, profissional e de cultura social.

Editadas em inúmeros capítulos, As memórias de um condenado (01-01 a 07-06 de 1882, no diário do irmão teatrólogo) foram um sucesso de público e um escândalo de crítica. A aproximação do folhetim com o leitor ia contra a 'aura' de apartado do mundo. A íntima relação entre autor, obra de arte e público caracteriza a literatura de jornal. Tanto assim que o folhetim manobrava, em campo escorregadio (o olho desconfiado da crítica já o reconhecia como escritor de talento, por isso, pertencente a uma elite, cuja obrigação era não se macular com os apelos do público leitor mais voraz "de carne sangrenta”, como afirma Araripe Junior).

Naquela ficção, uma infinidade de acontecimentos, seduções, mortes, adultérios, para o fim último de denunciar os prejuízos do sentimentalismo na prática, por um lado, e a ociosidade das classes dominantes, por outro. No meio, equilibrando o labirinto de acontecimentos numa longa linha temporal, a vida desequilibrada, devassa e recheada de contravençóes da jovem Ambrosina, que vem a transformar-se na grande cortesã condessa Vésper. Esses são os ingredientes para a confecção de capítulos cuja publicação pode até tomar um ano de duração (é o caso de Bodas de neve, sendo publicado em $O$ Imparcial, de 01-01-1932 a 24-12-1932).

Publicado em formato de livro, o sucesso que fez aumentar a tiragem de $A$ gazetinha de um vintém (que em 1882 custava 40 réis, ou seja, 2 vinténs), não alcança unidade romanesca (não impedindo o sucesso de inúmeras reedições), porque a conclusão de um capítulo ambientado no Brasil e o início de outro na Argentina, ou a apresentaçáo de um personagem novo faziam parte do aprisionamento do leitor em curiosidades, suspensóes, reticências, que, por sua vez, caracterizam a técnica do folhetim. A transformação para o romance cria problemas de gênero. O que era uma personagem que compunha um quadro maior de enfraquecimento social (a narrativa, no jornal, fazia uma crítica à sociedade - logo, estava indo contra, o que era o receituário da Gazetinha: provocar polêmicas), sem aquele elemento de combate extraliterário, tornava-se uma peça questionável na inteireza do romance; mais grave, afigura-se em narrativa de uma mulher-demônio, ícone do movimento que Aluísio critica - o romantismo. Ou seja, o que se quer criticar, aparece como a forma romanesca.

O primeiro capítulo chama-se "Memórias de um condenado", que, no folhetim, era "Um caso extraordinário", segundo Luiz Santa Cruz ${ }^{3}$. O romancista recebe uma carta misteriosa, acontecimento comum aos romances-folhetins de Joaquim Manuel de 
Macedo (Senso do dever) e de José de Alencar (Senhora). Nela, está a história que se vai contar. O romancista leitor de cartas é assim apresentado:

Pode ser que me engane, mas a um rapaz, sem bens de fortuna e sem influência de família, que teve a coragem de reagir contra velhos preconceitos do nosso país, abrindo caminho com a sua pena de escritor transformada em picareta, e posta só a serviço dos fracos e desprotegidos, não pode ser indiferente à desgraça de quem se vê encerrado entre as negras paredes de uma prisão, sem outro companheiro além da própria consciência que o tortura. (p. 15).

Pelo texto, a mensagem deixa claro a quem se destina a carta, que difere do folhetim, explicitamente endereçada a ninguém menos que o próprio Aluísio Azevedo. A intrusão de informação biográfica inclui o leitor em querela mais próxima da realidade, recurso comum aos escritos ficcionais e folhetinescos, e ironiza, com a 'picareta', os conselhos dados pelos críticos de São Luís do Maranhão, quando publica $O$ mulato, os mesmos que Azevedo também combate, com seu romance, n’ A gazetinha. O manuscrito conta a história de uma tragédia já ocorrida e também de quem a provocou:

$\mathrm{O}$ verdadeiro culpado foram os elementos em que formou e desenvolveu o meu ser, foi o ardente romantismo em que palpitaram aqueles a quem coube a formação do meu temperamento e do meu caráter, foi a ausência de trabalho, foi a má educação sentimental, e foi o excesso de dinheiro (p. 16).

Assim, a narrativa promete estabelecer uma série de exemplos didáticos, onde serão expurgados o romantismo, a falta de caráter e a ociosidade das classes abastadas da Corte. Em meio a todos os recursos do romance-folhetim - retornos ao passado, avanços rápidos, longas explicaçóes, sustos, surpresas e sobressaltos -, uma gama de personagens bondosos, injustiçados, vingativos, rancorosos, generosos, conta-se a história de Gabriel e Ambrosina.

Filhos de famílias inimigas, os protagonistas se apaixonam quando Ambrosina escolhe casar com outro pela aparente superioridade financeira. Por um golpe ficcional, Leonardo, o noivo premiado, enlouquece na noite de núpcias, deixando lugar para o moço Gabriel se aproximar, porém impossibilitando a via matrimonial. A saída para as personagens é o escandaloso amor clandestino, que a filha do comendador Moscoso não tenciona recusar. $\mathrm{O}$ narrador descreve o encontro entre máe e filha em pleno concubinato:

A viúva do comendador sentia-se constrangida em meio da opulência arrebicada e impudica daquela instalação; tapetes, móveis, quadros, tinha tudo um certo caráter 
leviano, certo ar de vida de atriz moça e bonita, que tresandava a escândalo. (...)

- Então o que quer dizer tudo isto? Perguntou-lhe a mãe.

- O que vê!....

- Mas com quem moras aqui?

- Com Gabriel.

— Teu amante!...

- Sim, porque não pode ser meu marido. [...].

- E se ele te abandonar?

- Que abandone!

— E sabes tu o que isso será? (p. 143-4).

Ambrosina trai Gabriel numa festa preparada por esta em sua casa. O que chama a atenção é a facilidade com que a heroína constrói uma atribulada atividade amorosa. De Gabriel para Melo Rosa, deste para Laura, para os amantes como cortesã de luxo, o sobrinho do imperador seria o auge, e Gustavo - um escritor que pesquisa material para seus romances naturalistas nas estalagens pobres que proliferam no Rio de Janeiro, na segunda metade do século XIX. Ele também é parte biográfica do futuro Aluísio de $O$ cortiço. A vida amorosa atribulada é registrada num diário. Lido para o desiludido amante, ela confessa a propensão pelo prazer destrutivo, quando se viu apaixonada por Laura.

"Foi o meu único amor. Jamais em delírio de sentido, paixão, esquecimento de tudo, a alma e carne se fundiram numa só lava de desejo insaciável e ardente, como às nossas sucedeu para sempre nessa noite imensa, misteriosa, revolta e sombria como um oceano maldito.

"Fugimos as duas para a Europa.

"O pai de Laura morreu de desgosto.

"E para nós outras abriu-se uma estranha vida de delícias transcendentais e cruéis. Primaveramos em Nice e fomos de verão a Paris. O velho mundo, sistematicamente orgíaco, nos era indiferente e banal. Vivíamos uma para a outra" (p. 315).

Gustavo, não suportando conhecer a vida pregressa da protagonista e vendo o destino terrível dos que se aproximam da bela cortesã, realiza um passeio fúnebre pelas ruas do centro do Rio de Janeiro (Lavradio, Carioca, Paço Imperial), toma a balsa para Niterói e salta para a morte na baía de Guanabara. A diferença do folhetim para o romance é gritante nessa passagem. No livro, a tragédia se dá logo após a leitura do diário. No jornal, a falência financeira e moral motiva o suicídio, por causa do roubo de uma grande quantia para satisfazer os caprichos da cortesã. O livro impóe um julgamento mais moralista da 
relação amorosa das duas jovens; com requintes de vampirismo, uma vez que é a luxúria de Ambrosina, pela 'colheita' dos beijos apaixonados, que causa a morte de Laura.

$\mathrm{Na}$ decadência da condessa, pelo passar dos anos que apagam a beleza e de Gabriel, por causa da falência do banco Mauá, os dois amantes se unem novamente. Agora, o que parecia uma união estabilizada pelo sofrimento e luxúria de ambos, torna terrível o relacionamento na vida pacata. A tônica do último desejo da condessa é medida pela ambição pelos belos e valiosos brincos Farani, que, no momento de desespero, o protagonista transforma em balas de revólver e assassina a protagonista. Terminada a carta, o romancista é informado que Gabriel comete suicídio na prisão, pondo termo à história da protagonista-demônio e sua trajetória de pecados.

As mortes por doença, assassinatos e suicídios caracterizam o gênero do romancefolhetim, aproximando-o do gênero policial (o cotidiano de uma época que tinha uma expectativa de vida de 33 anos, mais ou menos). A condessa Vésper é construída para ser devorada pelo leitor - para isso, ilustrando com algumas ideias e moralidades dele e para ler o jornal, como um todo. Uma das explicaçóes está na necessidade financeira comum a todo escritor brasileiro daquela época, e ainda náo sanada de todo na contemporaneidade: se não fosse de família abastada nem tivesse um bom emprego público, daqueles pelos quais Alencar fez a personagem Fernando Seixas tomar consciência de sua inutilidade: o marido de Aurélia Camargo saía às nove horas de casa e retornava às três, com direito a um par de horas para o charuto. Assim, algumas reflexóes podem ser feitas sobre o romance no jornal, sua transposição para o livro e o papel da literatura na circulação entre os dois meios.

É preciso lembrar que, como bem expóe o folhetim, Ambrosina é personagem que justifica o triste fim. O jornal Gazetinha, onde a heroína nasce, tem duas interrupçóes - entre 1880 e 1882 e em 1883 - devido a problemas financeiros. O romancista que a concebe é filho de família humilde em atividade profissional espinhosa. Eles constituem entidades letradas problemáticas. Para as suas sobrevivências, precisam fazer o jogo próprio da condessa Vésper: seduzir, sendo seduzidos pela sociedade, que caracteriza e dá contornos ao que chamamos literatura.

\section{NOTAS}

\section{SOR}

1 FLAUBERT, Gustave. Madame Bovary. 9. ed. Rio de Janeiro: Ediouro, 1997. SHAKESPEARE, Willian. Otelo. Trad. Beatriz Viégas-Faria. Porto Alegre: L \& PM, 1999. (Col. L \& PM Pocket, 174). ASSIS, Machado de. Dom Casmurro. 30. ed. São Paulo: Ática, 1996. HOMERO. Ilíada (em versos). 2. ed. Tradução de Carlos Alberto Nunes. Rio de Janeiro: Ediouro, 2001.

2 NETTO, Coelho. A conquista. 2. ed.Porto: Chardron, 1913, p. 40. 
3 CRUZ, Luiz Santa. Introdução. In: AZEVEDO, Aluísio. A condessa Vésper. 10. ed. São Paulo: Martins, 1973, p. 10.

\section{Resumo}

De forma alguma é incomum a literatura conceber modelos femininos negativos como oportunidade didática. Em A condessa Vésper (1882), o então escritor polêmico Aluísio Azevedo (1857-1913) constrói uma protagonista-demônio. Ao feitio dos futuros vilóes dos romances de Joáo Ubaldo Ribeiro, em Ambrosina estão todos os atributos da maldade: ambiciosa, mentirosa, falsa, adúltera, ladra, prostituta, sedutora, homossexual. Ela é hiperbolicamente negativa. Chamá-la de dissimulada seria uma ironia, e não uma adjetivação. A questão não é estudar o caráter da maldade da protagonista do folhetim Memórias de um condenado (primeiro título), mas perceber, nessa construção quase carnavalesca, as intençôes de recepção do romancista. Ele satisfaz uma classe leitora cuidadosamente estudada e tenta, pelas entrelinhas da narrativa, escrever uma obra emancipatória, no dizer de Hans Robert Jauss. O jornal é o espaço onde se dará o conflito que, para acerto do teórico da recepção, atrai a história da literatura para ler as obras seguindo códigos sociais à risca.

Palavras-chave: A condessa Vésper; Romance; Personagem feminina; Literatura brasileira.

\section{Abstract}

Uncommom isn't the literature to make females negatives models with opportunity to social learn. In the novel $A$ condessa Vésper (1882), on that occasion, the polemic writer Aluísio Azevedo (1857-1913) building a demon protagonist. At same profile of the João Ubaldo Ribeiro's futures villains, in Ambrosina are every wickedness qualifications: ambitious, lying, untrue, adulterous, stealing, prostitute, seducer, homosexual. She's the negative hyperbolic. Denominate her of dissimulated would be a irony, and don't a adjective. The question not is to study the protagonist's character of the wickedness of feuilleton Memórias de um condenado (first title), but to understand, in the construction almost carnival, the intentions of novelist's reception. He satisfy a reader class carefully studied e try, in the narrative's interlineations, to write a emancipated work, in the Hans Robert Jauss's words.

Keywords: The Countess Vesper; romance; female character; brazilian literature.

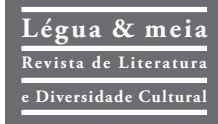

PINHO, Adeítalo Manoel. A condessa da maldade: formação da personagem feminina no romance brasileiro do século XIX. Légua \& meia: Revista de literatura e diversidade cultural. Feira de Santana: UEFS, A. 13, nº 6, 2014, p 165-172.

Adeítalo Manoel Pinho é Professor Adjunto de Literatura Brasileira da UEFS; Doutorado em Letras pela Pontifícia Universidade Católica do Rio Grande do Sul; autor de Perfeitas Memórias: literatura, experiência e invenção (7 Letras, 2011). Tem vários trabalhos publicados em periódicos e jornais. É o atual coordenador do Programa de Pós-Graduação em Estudos Literários da UEFS. 